\title{
Romatoid Artrit Hastalarının Metotreksat Kullanımı ile İlgili Farkındalıkları*
}

\author{
Belkıs Nihan COŞKUN, Burcu YAĞIZ, Yavuz PEHLIVAN, Ediz DALKILIÇ \\ Bursa Uludağ Üniversitesi Tıp Fakültesi, İç Hastalıkları Ana Bilim Dalı, Romatoloji Bilim Dalı, Bursa.
}

\begin{abstract}
ÖZET
Calıșmanın amacı, Romatoid artrit (RA) tedavisinde standart ilaç olan metotreksat (MTX) ile ilgili RA hastalarının bilgilerini bir anket aracılığıyla değerlendirmektir. Ağustos-Ekim 2017 tarihinde bir üniversite hastanesinde RA tanısı ile MTX kullanan hastalardan, MTX'in etki mekanizması, uygulama şekli, ilaç etkileşimi, yan etkileri, hastaların izlenme sıklı̆̆ı ve yapılması gereken yaşam tarzı değişiklikleri ile ilgili soruları içeren anketi yanıtlamaları istendi. Yüz altmış iki hasta (144 kadın) çalışmaya dahil edildi. Ortalama hasta yaşı 52 (18-77), ortalama hastalık süresi 10.3 (1-40) yıl ve ortalama MTX kullanma süresi 7,1 (1-38) yıl idi. MTX'in hastalığı düzenleyen antiromatizmal bir ilaç olduğunu \%50 hasta doğru yanıtladı. Uygulama sıklığının haftalık olduğunu \%85; folik asid kullanma gerekçesinin, tedavi toksisitesini azaltmak olduğunu ise $\% 19$ hasta belirtti ve yine sadece $\% 11$ 'i trimetoprimin kontraendike olduğunu biliyordu. Hematolojik risklerden \%11'i haberdardı ve \%11'i aşırı duyarlılık pnömonisi riskinin farkındaydı. Laboratuvar testleri ile ilgili \%51'inin bilgisi vardı. Doğurganlık çağında kadın ve erkeklerin MTX kullanırken kontrasepsiyon kullanması gerekliliğini bilenler \%20 idi. \%34’ü alkol tüketiminin sinırlı olması gerektiğini belirtti. Erkekler ve eğitim seviyesi yüksek olanlar istatistiksel olarak daha yüksek oranda doğru cevap verdi $(p=0.019$, $\mathrm{p}=0.000$ ). Günlük pratikte RA hastalarında sıklıkla kullanılan MTX hakkında hastaların yetersiz bilgiye sahip olduğu görüldü. Özellikle ciddi yan etkiler, ilaç etkileşimleri ve doğum kontrolü gibi önemli konularda eksiklikler vardı. MTX'e ilişkin hasta bilgisi farklı eğitim araçlarını kullanarak düzenli olarak kontrol edilmeli ve desteklenmelidir.
\end{abstract}

Anahtar Kelimeler: Farkındalık. Metotreksat. Romatoid artrit.

Awareness of Rheumatoid Arthritis Patients About Methotrexate Use

\section{ABSTRACT}

The aim of the study is to evaluate the rheumatoid arthritis (RA) patients' knowledge about methotrexate (MTX), the standard drug in the treatment of RA, through a questionnaire. In August-October 2017, patients who used MTX with a diagnosis of RA in a university hospital were asked to answer questionnaire about the mechanism of action of MTX, administration method, drug interaction, side effects, frequency of follow-up of patients and changes to the lifestyle that should be done. One hundred and sixty-two patients (144 women) were included in the study. The mean patient age was 52 (18-77) years, the mean disease duration was 10.3 (1-40) years, and the mean duration of MTX use was 7.1 (1-38) years. $50 \%$ of the patients correctly answered that MTX is an anti-inflammatory drug that regulates the disease. $85 \%$ of patients correctly responded to the weekly application frequency correctly.; $19 \%$ of the patients stated that the reason for using folic acid was to reduce the toxicity of the treatment and again only $11 \%$ knew that trimethoprim was contraindicated. $11 \%$ were aware of the hematological risks and $11 \%$ were aware of the risk of hypersensitivity pneumonia. $51 \%$ of them had knowledge about laboratory tests. $20 \%$ of women and men of childbearing age knew that they should use contraception while using MTX. 34\% stated that alcohol consumption should be limited. Men and those with a high level of education gave a statistically higher rate of correct answers. $(\mathrm{p}=0.019, \mathrm{p}=0.000)$ It was observed that the patients had insufficient knowledge about MTX, which is frequently used in RA patients in daily practice. There are shortcomings on important issues, especially serious side effects, drug interactions, and birth control. Patient information regarding MTX should be checked and supported regularly by using different training tools.

Key Words: Awareness. Methotrexate. Rheumatoid arthritis.

Geliş Tarihi: 07.Aralık.2020

Kabul Tarihi: 18.Ocak.2021

Dr. Belkıs Nihan COŞKUN

Bursa Uludağ Üniversitesi Tıp Fakültesi,

İç Hastalıkları Ana Bilim Dalı,

Romatoloji Bilim Dalı,

Bursa.

Tel: 05332255513

E-posta: belkisnihanseniz@hotmail.com
* Uludağ İç Hastalıkları Günleri'nde (Uludağ, Bursa, 2018) sözlü bildiri olarak sunulmuştur.

\section{Yazarların ORCID ID Bilgisi:}

Nihan COSKUN: 0000-0003-0298-4157

Burcu YAĞIZ: 0000-0002-0624-1986

Yavuz PEHLIVAN: 0000-0002-7054-5351

Ediz DALKILIÇ: 0000-0001-8645-2670 
Metotreksat (MTX), romatoid artrit (RA) tedavisinin vazgeçilmez ilacıdır ${ }^{1}$. RA tedavisinde 30 seneyi aşkın bir süredir yer almasına ve bu sürede birçok yeni tedavinin kullanıma girmesine rağmen hala ilk seçenek konumundadır. MTX oral ya da parenteral (subkutan veya intramüsküler) olarak kullanılabilen bir geleneksel hastalığı modifiye edici antiromatizmal ilaçtır (DMARD). Tek başına veya diğer geleneksel DMARD'lar veya biyolojik tedaviler ile kombine olarak kullanılabilir ${ }^{2-4}$.

Gastrointestinal rahatsızlık, bulantı, oral ülserler, saç dökülmesi, transaminazlarda hafif yükselme en yaygın minör yan etkilerdir ve hastaların tedaviye uyumunu azaltabilir ${ }^{3}$. Başta oral ülserler olmak üzere gastrointestinal yan etkileri azaltmak, transaminaz yüksekliğine bağlı yan etkileri önlemek ve etkinlik kaybını ortadan kaldırmak için MTX tedavisi ile birlikte folik asit kullanımı önerilmektedir ${ }^{5}$. Daha nadir olarak hipersensitivite pnömonisi ve pansitopeni gibi ciddi yan etkiler görülebilir ${ }^{3}$.

MTX doğru kullanıldığında oldukça güvenilir bir ilaç olmasına rağmen yanlış kullanılması durumunda pansitopeni, mukozit, ateş, hepatotoksisite, renal yetmezlik bulgularının görülebildiği intoksikasyon tablosu gelişebilir. Bir çalışmada, MTX intoksikasyonu gelişen 31 hasta takip edilmiş ve 4 hastanın tedaviye rağmen hayatını kaybettiği görülmüştür ${ }^{6}$.

MTX teratojendir ve gebelikte kullanılmamalıdır. Doğurganlık çağındaki hastalar kontrasepsiyon konusunda uyarılmalıdır. Trimetoprim MTX ile aynı enzimi inhibe etmektedir. İki ilacın beraber kullanımı toksisite riskini artırabilmektedir. Trimetoprim/ sulfametoksazol (TMP/SMX), MTX kullanan hastalarda kontrendikedir. Diyaliz uygulanan ve kreatinin klirensi $<30 \mathrm{~mL} / \mathrm{dk}$ olan hastalarda MTX kullanılmamalıdır. Alkol bir hepatotoksindir. MTX ile birlikte alkol alımı hepatotoksisite riskini arttırabilmektedir. Alkol alımından kaçınılmalı veya sinırlandırılmalıdır².

MTX, 1980'li yıllardan beri başta RA olmak üzere pek çok romatolojik hastalığın tedavisinde etkin olarak kullanılmasına rağmen hastaların MTX hakkındaki bilgileri üzerine çok az çalışma yayınlanmıştır $^{7-10}$. Çalışmamızın amacı, RA hastalarımızın, en yaygın kullanılan DMARD olan MTX hakkındaki bilgilerini bir anket aracılığıyla değerlendirmektir. Böylelikle hangi alanda daha az bilgi sahibi olunduğunu göstermek ve buna etki eden klinik özellikleri belirlemektir.

\section{Gereç ve Yöntem}

\section{Hasta seçimi:}

Bu çalışma yerel etik kuruldan onay alındıktan sonra Ağustos-Ekim 2017 tarihinde bir üniversite hastanesinde yapıldı. RA tanısı ile tek başına veya diğer DMARD'lar ya da biyolojikler ile kombine olarak MTX kullanan hastalar anket çalışmasına katılmaya davet edildi.
Anket:

Fayet ve arkadaşlarının 183 RA hastasında MTX ile ilgili bilgi düzeyini ölçmek için yapmış oldukları anket soruları kullanıldı ${ }^{9}$. Anketin soruları MTX ilacı ile ilgili bilgiler (uygulama yöntemi, dozu, ilaç etkileşimleri ve folik asit ile kombinasyonu), yan etkiler, ilaç kullanırken izleme sıklığı, yaşam tarzında yapılması gereken değişiklikleri (alkol, doğum kontrolü) içermektedir. Ayrıca aşılama, olası yan etkiler, diş çekimi ve cerrahiye hazırlık prosedürü ile ilgili sorular da mevcuttur. Ankette her sorunun bir doğru cevabı vardır. Anketin sonunda MTX ile ilgili daha fazla bilgi almak için bir hemşire ile görüşmek isteyip istemedikleri de soruldu.

\section{Skorlama:}

Soruların doğru cevapları 1 yanlış cevapları 0 olarak skorland1. Sonuçlar toplanarak bir puan elde edildi. Bu puanlama sonucunda ortancanın üzerinde olan 5 ve üzerinde yanıt verenler yüksek doğru cevap veren grup, 5'in altında olanlar da düşük doğru yanıt veren grup olmak üzere iki gruba ayrıldı.

\section{Verilerin Değerlendirilmesi:}

İstatistiksel analizlerde SPSS 23.0 programı kullanıldı. Çalışma verileri değerlendirilirken tanımlayıcı istatistiksel metotlar (ortalama, standart sapma, medyan, frekans, yüzde, minimum, maksimum) kullanıldı. Verilerin normal dağılıma uygun olup olmadığını analiz etmek için Shapiro-Wilk testi kullanıldı. Veriler normal dağılım göstermediğinden analizlerde nonparametrik testler kullanıldı. Birbirinden bağımsız iki grubun nitel değişkenleri karşılaştırılırken Ki-kare testi, nicel değişkenlerinin ortalamaları karşılaştırılırken Mann-whitney u testi kullanıldı. Hastaların iki grup arasındaki etkili faktörlerin incelenmesinde, tek değişkenli analiz ve daha sonra da çok değişkenli analiz, binary lojistik regresyon analizi (Forward LR) kullanıldı. İstatistiksel anlamlılık değeri $\mathrm{p}<0.05$ olarak kabul edildi.

\section{Bulgular}

Çalışmaya toplam 162 RA tanılı hasta dahil edildi. Hastaların \%88,9'u kadın olup hastaların özellikleri Tablo I'de belirtilmiştir. Sorulara verilen doğru ve yanlış cevap oranları Tablo II'de belirtilmiştir. Yanıtlar; ilacın etki mekanizması, yan etkiler ve yaşam tarzı olmak üzere üç ana başlıkta toplanmıştır. Yüksek doğru yanıt veren grup ile düşük doğru yanıt veren grubun özellikleri karşılaştırıldı (Tablo III). Erkeklerin, aktif çalışanların ve eğitim durumu daha yüksek olanların anket sorularını istatistiksel olarak doğru yanıtladığ1 görüldü (Sırasiyla p=0.019, p=0.007, p=0.000). Hastaların yaşı, RA hastalık süresi, MTX kullanım süresi, MTX dozu ve kullanım şekli karşılaştırıldığında iki grup arasında anlamlı farklılık saptanmadı. Tek değişkenli ve çok değişkenli analizlerde de cinsiyet ve 


\section{Romatoid Artrit ve Metotreksat Farkındalığı}

eğitim seviyesinin yüksek yanıt oranıyla yakından ilişkili olduğu saptandı (Tablo IV). Anketin sonunda hastalara eğitim hemşiresinden bilgi almak isteyip istemediği soruldu. Hastaların \%80‘i bilgi almak istedi.

Tablo I: Hasta özellikleri.

\begin{tabular}{|l|l|}
\hline Yaş ortalaması & $52.39 \pm 13.03$ yaş (18-77) \\
\hline Kadın & $144(\% 88.9)$ \\
\hline Romatoid artrit tanı süresi & $10.31 \pm 7.26$ yı (1-40) \\
\hline MTX* kullanım süresi & $7.1 \pm 5.91$ yıl (1-38) \\
\hline MTX dozu & \\
$<10 \mathrm{mg}$ & $56(\% 34.6)$ \\
$>10 \mathrm{mg}$ & $106(\% 65.4)$ \\
\hline MTX & $119(\% 73.5)$ \\
Oral & $43(\% 26.5)$ \\
Subkutan & $27(\% 16.7)$ \\
\hline Meslek \% & $109(\% 67.3)$ \\
Çalışıyor & $26(\% 16)$ \\
Çalısmıyor & $101(\% 62.3)$ \\
Emekli & $44(\% 27.2)$ \\
\hline Eğitim seviyesi \% & $17(\% 10.5)$ \\
Illkokul & \\
Ortaokul-Lise & \\
Üniversite & \\
\hline
\end{tabular}

*MTX: Metotreksat

Tablo II: Anket cevapları.

\begin{tabular}{|c|c|c|c|}
\hline & \begin{tabular}{|c|} 
Doğru \\
cevap \\
Yüzdeleri \\
$(\%)$ \\
\end{tabular} & \begin{tabular}{|c|} 
Yanlış \\
cevap \\
Yüzdeleri \\
$(\%)$ \\
\end{tabular} & $\begin{array}{c}\text { Cevapsız } \\
(\%)\end{array}$ \\
\hline \multicolumn{4}{|l|}{ Etki mekanizması } \\
\hline MTX* bir DMARD'dır & 50.6 & 9.9 & 39.5 \\
\hline Etki başlama süresi & 27.2 & 14.8 & 58 \\
\hline Semptom geçince kesilmemeli & 21 & 21 & 58 \\
\hline Doz ağrıya göre ayarlanmamalı & 42.6 & 19.8 & 37.7 \\
\hline Maksimum doz & 22.2 & 6.8 & 71 \\
\hline Haftalık uygulama & 85.8 & 6.2 & 8 \\
\hline \multirow{3}{*}{$\begin{array}{l}\text { Folik asid MTX toksisitesini azaltır } \\
\text { Yüksek dozda etkinliği azaltır } \\
\text { MTX etkinliğini artırmaz }\end{array}$} & 19.1 & 8.6 & 72.2 \\
\hline & 4.3 & 15.4 & 80.2 \\
\hline & 9.9 & 12.3 & 77.8 \\
\hline Trimetoprim ile birlikte kullanılmamalı & 11.1 & 7.4 & 81.5 \\
\hline İlaç etkileşimi olmaz -analjezik & 29 & 17.9 & 53.1 \\
\hline NSAID** & 26.5 & 16.7 & 56.8 \\
\hline Kortikosteroidler & 27.8 & 14.2 & 58 \\
\hline DMARD*** & 26.5 & 19.1 & 54.3 \\
\hline Diğer antibiyotiklerle etkileşim olmaz & 11.1 & 13.6 & 75.3 \\
\hline \multicolumn{4}{|l|}{ Yan etkiler } \\
\hline Hematolojik & 11.7 & 5.6 & 82.7 \\
\hline Hipersensitivite pnömonisi & 11.7 & 13.6 & 74.7 \\
\hline Doğru olmayan yan etkiler: kanser & 20.4 & 7.4 & 72.2 \\
\hline İnfarkt & 17.3 & 7.4 & 75.3 \\
\hline Peptik ülser & 9.9 & 26.5 & 63.6 \\
\hline Laboratuvar testlerinin yapılması & 51.9 & 40.7 & 7.4 \\
\hline \multicolumn{4}{|l|}{ Yaşam tarzı } \\
\hline Kontrasepsiyon gerekliliği & 20.4 & 9.3 & 70.4 \\
\hline $\begin{array}{l}\text { Erkekler kontrasepsiyondan } 3 \text { ay önce } \\
\text { kesmeli }\end{array}$ & 56.2 & 20.4 & 23.4 \\
\hline Alkol kısıtlanmalı & 34.6 & 5.6 & 59.9 \\
\hline Aşılama yapılabilir & 18.5 & 9.9 & 71.6 \\
\hline Cerrahiden 2 ay önce kesilmemeli & 6.8 & 11.7 & 81.5 \\
\hline Diş çekiminden önce kesilmemeli & 12.3 & 9.3 & 78.4 \\
\hline
\end{tabular}

*MTX: Metotreksat, ** NSAID: Nonsteroid antiinflamatuar ilaç, *** DMARD: Geleneksel hastalı̆̆l modifiye edici antiromatizmal ilaç
Tablo III: Doğru yanıt düzeylerine göre karşılaştırma

\begin{tabular}{|c|c|c|c|}
\hline & Grup 1* & Grup 2** & $p$ \\
\hline Yaş & $53.98 \pm 13.96$ & $50.95 \pm 12.03$ & $0.105^{a}$ \\
\hline RAđ hastalık süresi & $10.16 \pm 8.04$ & $10.44 \pm 6.52$ & $0.425^{a}$ \\
\hline MTXף ฯ kullanım süresi & $6.70 \pm 5.54$ & $7.47 \pm 6.24$ & $0.417^{a}$ \\
\hline \multicolumn{4}{|l|}{ Cinsiyet } \\
\hline Kadın $(n=144)$ & $73(\%)$ & $71(\%)$ & \multirow[t]{2}{*}{$0.019 \mathrm{~b}$} \\
\hline Erkek $(n=18)$ & $4(\%)$ & $14(\%)$ & \\
\hline \multicolumn{4}{|l|}{ Çalışma durumu } \\
\hline Çalışıyor (n=27) & $7(\%)$ & $20(\%)$ & \multirow[t]{3}{*}{$0.007 \mathrm{~b}$} \\
\hline Çalışmıyor $(n=109)$ & $61(\%)$ & $48(\%)$ & \\
\hline Emekli $(n=26)$ & $9(\%)$ & $17(\%)$ & \\
\hline \multicolumn{4}{|l|}{ Eğitim durumu } \\
\hline İkokul (n=101) & $58(\%)$ & $43(\%)$ & \multirow[t]{3}{*}{$0.000 \mathrm{~b}$} \\
\hline Ortaokul/Lise $(n=44)$ & $17(\%)$ & $27(\%)$ & \\
\hline Üniversite (n=17) & $2(\%)$ & $15(\%)$ & \\
\hline \multicolumn{4}{|l|}{ MTX doz } \\
\hline$<10 \mathrm{mg}(n=56)$ & $26(\%)$ & $30(\%)$ & \multirow[t]{3}{*}{$0.485^{b}$} \\
\hline$\geq 10 \mathrm{mg}(n=106)$ & $51(\%)$ & $55(\%)$ & \\
\hline \multicolumn{3}{|l|}{ MTX kullanım şekli } & \\
\hline Oral $(n=119)$ & $58(\%)$ & $61(\%)$ & \multirow[t]{2}{*}{$0.370^{b}$} \\
\hline Subkutan $(n=43)$ & $19(\%)$ & $24(\%)$ & \\
\hline
\end{tabular}

* Grup 1: Doğru yanit skoru $<5$, ** Grup 2: Doğru yanit skoru $\geq 5$,

${ }^{a}$ Mann- whitney u testi, ${ }^{b}$ Ki-kare testi,

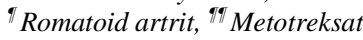

Tablo IV: Tek değişkenli model ile çok değişkenli indirgenmiş model karşılaştırılması

\begin{tabular}{|c|c|c|c|c|c|c|}
\hline & \multicolumn{3}{|c|}{$\begin{array}{l}\text { Tek Değişkenli } \\
\text { Model }\end{array}$} & \multicolumn{3}{|c|}{$\begin{array}{c}\text { Çok Değişkenli } \\
\text { İndirgenmiş Model }\end{array}$} \\
\hline & $\mathrm{OR}^{*}$ & $95 \% \mathrm{GA}^{\star \star}$ & $p$ & OR & $95 \% \mathrm{GA}$ & $p$ \\
\hline Cinsiyet & 4.41 & $1.26-15.39$ & 0.02 & 3.77 & $1.14-12.48$ & 0.03 \\
\hline Yaş & 0.98 & $0.95-1.02$ & 0.50 & & & \\
\hline Çalışma durumu & 0.91 & $0.44-1.88$ & 0.80 & & & \\
\hline Eğitim durumu & 2.58 & $1.45-4.60$ & 0.001 & 2.62 & $1.54-4.46$ & 0.000 \\
\hline RA` tanı süresi & 1.02 & $0.96-1.08$ & 0.45 & & & \\
\hline $\begin{array}{l}\text { MTX }{ }^{\mp \pi} \text { kullanım } \\
\text { süresi }\end{array}$ & 1.00 & $0.93-1.07$ & 0.93 & & & \\
\hline MTX doz & 0.89 & $0.26-3.07$ & 0.85 & & & \\
\hline MTX oral/sc थाזा & 1.26 & $0.57-2.75$ & 0.56 & & & \\
\hline
\end{tabular}

*OR: Odds ratio **GA: Güven aralığl

" Romatoid artrit, " Metotreksat, "ศศ Subkutan

\section{Tartışma ve Sonuç}

RA hastalarımızın MTX ile ilgili bilgi düzeylerinin düşük olduğu gözlemlendi. Özellikle en ciddi yan etkiler (hematolojik ve aşırı duyarlılık pnömonisi), TMP/SMX ile etkileşimler, diğer antibiyotiklerle etkileşimlerle ilgili bilgiler daha da sınırlıydı. Eğitim seviyesi arttıkça ve erkek cinsiyette bilgi düzeyi daha yüksekti. Bununla birlikte, MTX'in etki mekanizmasının, kullanım şeklinin ve dozun ağrıya göre ayarlanmaması gerektiğinin ve laboratuvar çalışması izleme kılavuzlarının göreceli olarak daha fazla bilinmesi mutluluk vericidir.

Romatoloji pratiğinde MTX çok önemli bir yere sahiptir. Literatürde hastaların MTX hakkındaki bilgilerini ölçen sınırlı sayıda çalışma mevcuttur ${ }^{7-8-10}$. Biz de kendi hastalarımızın MTX hakkındaki bilgilerini ölçtük ve eğitim seviyesi ve erkek cinsiyet dışında, yaş, 
RA tanı süresi, MTX kullanım süresi, doz ve kullanım şeklinde anlamlı farklılık bulamadık. Eğitim seviyesi arttıkça doğru cevap oranlarının artması beklenen bir sonuçtur. Hastalarımızın bilgi skor aralığı 0-20 arasındaydı. Ortalama doğru cevap 5 puandı. Barton ve arkadaşlarının yaptığı çalışmada katılımc1ların \%54'ünün MTX bilgi puan ortalaması 5 'in altındaydı (Aralık, 0 ila 10). Puanlardaki en önemli fark, yaştı. 55 yaş üzerindeki hastalar sorulara daha az yanıt vermişti. Cinsiyet, ırk / etnik köken veya hastalık süresine göre önemli bir farklılık bulunamadı ${ }^{8}$.

Araştırmalar, bir doktor tarafindan sözlü olarak sağlanan bilgilerin \%40-80'inin hemen unutulduğunu ve hatırlanan bilgilerin de yarısının yanlış olduğunu göstermektedir ${ }^{11}$. Burma ve ark çalışmasında 138 hastanın her biri MTX hakkında yazılı bilgi almış ve hepsi romatoloji hemşiresi tarafından görülmüş olmasına rağmen, 23 hasta yapılan ankette MTX hakkında yazıl1 bilgi almadıklarını veya romatoloji hemşiresi tarafindan görülmediklerini bildirmişler. Eğitim, cinsiyet, yaş, MTX dozu ve MTX süresi gibi değişkenlerde iki grup arasındaki önemli ölçüde farklılık saptanmamışt ${ }^{7}$. MTX, etkinliğine rağmen, hastaların \%70'inden fazlasında istenmeyen yan etkilere neden olmaktadır. Hastaların çoğunluğu ilacı kullanmaya devam etse bile; 2 y1l veya daha uzun süredir MTX kullanmış RA hastalarının değerlendirildiği sistematik bir incelemede, yan etkiler sebebiyle hastaların üçte birinde MTX'ın kesildiği görülmüştür ${ }^{12}$. Hastaların MTX'in yan etkileri ve potansiyel toksisitelerini anlamaması, MTX ile ilișkili yan etkilerin insidansını artırabilir ve dolayısıyla MTX kullanımını sınırlayabilir veya hastada olası gereksiz zarara neden olabilir. Hastalarımızın \%11'i hematolojik yan etkiler ve hipersensitivite pnömonisi hakkında bilgi sahibiydi. Ayrıca doğru olmayan yan etkilerden kanser gelişim riski, myokard infartüs riski ve peptik ülser riski gibi yan etkiler hakkında da çoğunlukla fikirleri yoktu.

İlaçların hatalı kullanımı hem birey hem de toplum için maliyetli olabilir. Romatoloji pratiğinde MTX kullanımının yaygın olması ve özellikle yanlış kullanım sonucunda ciddi yan etki potansiyeline sahip olabileceğinden kaliteli hasta eğitimi çok önemlidir? ${ }^{7}$. Kivity ve ark 28 hastada düşük doz MTX toksisitesinin klinik özelliklerini, risk faktörlerini ve sonuçlarını araştırdı. Düşük doz MTX toksisitesinin en yaygın belirtisi olan pansitopeninin hastaların \%78,5'inde görüldüğünü bildirdi. Doz hatasının önemli potansiyel risk faktörlerinden biri olduğuna dikkat çekildi. Yedi $(\% 25)$ hasta hayatını kaybetti ${ }^{13}$. MTX aslında doğru kullanıldığında göreceli olarak güvenli bir ilaçtır. Ancak, en önemli, hatta ölümcül olabilecek yan etkisi yanlıs kullanımdır. İlacın kullanımı ile ilgili hasta ve hasta yakınına ayrıntılı bilgi verilmeli, kullanım şemas1 yazılı olarak verilmelidir. Calıșmamızda hastalarımızın \%85'i haftada bir gün MTX kullanması gerektiğini biliyordu.
Çalışmamızın temel kısıtlılıkları, sınırlı sayıda hastada yapılmış olan yerel bir çalışma olması ve sonuçların genellenememesidir. Bu çalışma, hastaların MTX ile ilgili bilgilerini gözden geçirmek ve ilaç için bir tedavi eğitim programı tasarlamak için bir temel oluşturmak amacıyla yapılmıştır. Bu değerlendirmenin bulgusu, tedavi eğitim programını oluşturmak için bir temel olarak kullanılacaktır. Daha büyük ve daha çeşitli popülasyonlarla bazı doğrulama çalışmaları yapılarak daha da geliştirilebilir.

Sonuç olarak; RA hastalarımızın MTX ile ilgili bilgilerinin yetersiz olduğunu gördük. Özellikle kadınların ve düşük eğitim seviyesi olan hastaların daha iyi şekilde bilgilendirilmeleri ve gerekirse bu eğitimlerin düzenli hale getirilmesi ve her kontrolde gözden geçirilmesi gerekmektedir.

\section{Etik Kurul Onay Bilgisi:}

Onaylayan Kurul: Uludağ Üniversitesi Tıp Fakültesi Klinik

Araștırmalar Etik Kurulu.

Onay Tarihi: 22.08 .2017

Karar No: 2017-13/100

\section{Araştırmacı Katkı Beyanı:}

Fikir ve tasarım: B.N.C., B.Y.; Veri toplama ve işleme: E.D.;

Analiz ve verilerin yorumlanmasi: Y.P.; Makalenin önemli bölümlerinin yazılması: B.N.C., B.Y

Destek ve Teşekkür Beyanı:

Makalemiz çalışmalarına finansal destek sağlanmamıştır.

Çıkar Çatışması Beyanı:

Makale yazarlarının çıkar çatışması beyanı yoktur.

\section{Kaynaklar}

1. Smolen JS, Landewé R, Bijlsma J, et al. EULAR recommendations for the management of rheumatoid arthritis with synthetic and biological disease-modifying antirheumatic drugs: 2016 update. Ann Rheum Dis. 2017. https://doi.org/10.1136/annrheumdis-2016-210715

2. Cannella AC, O’Dell JR. Traditional DMARDs. In: Firestein GS, Budd RC, Gabriel SE, et al (Eds). Kelley and Firestein's Textbook of Rheu- matology. 10th ed. Philadelphia: Elsevier Inc. 2017. 958-982. Doi:10.1016/b978-0-323-31696- 5.00061-9.

3. Snow MH, Cannella AC. (2019) Systemic Antirheumatic Drugs. West S. (Eds) Rheumatology Sec- rets. 4th E. S. A. D; Philadelphia: Elsevier. 2019. 662-670.

4. Hazlewood GS, Barnabe C, Tomlinson G, et al. Methotrexate monotherapy and methotrexate combination therapy with traditional and biologic disease modifying antirheumatic drugs for rheumatoid arthritis: Abridged cochrane Systematic review and network meta-analysis. BMJ. 2016;353:i1777. https://doi.org/10.1136/bmj.i1777

5. Shea B, Swinden M V., Tanjong Ghogomu E, et al. Folic acid and folinic acid for reducing side effects in patients receiving methotrexate for rheumatoid arthritis. Cochrane Database Syst. Rev.2013(5):CD000951.

6. Dalkilic E, Coskun BN, Yağız B, et al. Methotrexate intoxication: Beyond the adverse events. Int J Rheum Dis. 2018:1557-1562. https://doi.org/10.1111/1756-185X.13339

7. Burma MR, Rachow JW, Kolluri S, Saag KG. Methotrexate patient education: A quality improvement study. Arthritis Rheum 1996; 9:216-222. https://doi.org/10.1002/15290131(199606)9:3<216::AID-ANR1790090310>3.0.CO;2-5 


\section{Romatoid Artrit ve Metotreksat Farkındalığı}

8. Barton JL, Schmajuk G, Trupin L, et al. Poor knowledge of methotrexate associated with older age and limited Englishlanguage proficiency in a diverse rheumatoid arthritis cohort. Arthritis Res Ther 2013;15(5):R157. https://doi.org/10.1186/ar4340

9. Fayet F, Savel C, Rodere M, et al (2016) The development of a questionnaire to evaluate rheumatoid arthritis patient's knowledge about methotrexate. J Clin Nurs 2016;25:682-689. https://doi.org/10.1111/jocn.12999

10. Sowden E, Hassan W, Gooden A, et al. Limited end-user knowledge of methotrexate despite patient education: An assessment of rheumatologic preventive practice and effectiveness. J Clin Rheumatol 2012;18:130-133. https://doi.org/10.1097/RHU.0b013e31824e1e63
11. Kessels RPC. Patients' Memory for Medical Information. J R Soc Med 2003;96:219-222. https://doi.org/10.1177/014107680309600504

12. Salliot C, Van Der Heijde D. Long-term safety of methotrexate monotherapy in patients with rheumatoid arthritis: A systematic literature research. Ann Rheum Dis 2009;68:1100-1104. https://doi.org/10.1136/ard.2008.093690

13. Kivity S, Zafrir Y, Loebstein R, et al. Clinical characteristics and risk factors for low dose methotrexate toxicity: A cohort of 28 patients. Autoimmun Rev 2014;13:1109-1113. https://doi.org/10.1016/j.autrev.2014.08.027 
